\title{
UPAYA PENINGKATAN KEMAMPUAN MEMBACA MELALUI BUKU CERITA BERGAMBAR PADA ANAK USIA DINI
}

\author{
Novalia Ungzilatun Nikmah \\ Psikologi Islam Fakultas Ushuluddin dan Dakwah IAIN Kediri \\ Email: novaliaungzila1999@gmail.com \\ Yuli Darwati \\ Psikologi Islam Fakultas Ushuluddin dan Dakwah IAIN Kediri \\ Email: yulidarwati73@gmail.com
}

\begin{abstract}
Early reading is a unique and important skill for children's language development, as well as a means of communication for humans. Individuals will acquire new information, knowledge and new experiences through reading. The main and fundamental problem in this study is that many children are not able to read fluently. This study is aimed at early childhood with reading delays. This study aims to determine the improvement of reading comprehension through the method of reading picture story books. The method used in this research is descriptive and qualitative methods, the data is collected through observation and documentation. Based on the results of study, it was found that there was an increase in reading comprehension with picture story books.
\end{abstract}

Keywords: Early reading, early childhood, storybook method

\begin{abstract}
Abstrak: Membaca permulaan merupakan suatu keterampilan unik dan penting bagi perkembangan bahasa anak, serta sebagai alat komunikasi bagi manusia. Individu akan memperoleh informasi, ilmu pengetahuan dan pengalaman baru melalui membaca. Permasalahan utama dan mendasar dalam penelitian ini adalah banyak anak yang belum mampu membaca secara lancar. Penelitian ini ditujukan untuk anak usia dini dengan keterlambatan membaca. Penelitian ini bertujuan untuk mengetahui peningkatan pemahaman membaca melalui metode membaca buku cerita bergambar. Metode yang digunakan dalam penelitian ini adalah metode deskriptif dan kualitatif, data dikumpulkan melalui observasi dan dokumentasi. Berdasarkan hasil penelitian didapatkan adanya peningkatan pemahaman baca dengan buku cerita bergambar.
\end{abstract}

Kata Kunci: Membaca permulaan, anak usia dini, metode buku cerita

\section{PENDAHULUAN}

Membaca merupakan salah satu kemampuan berbahasa tulis yang bersifat resertif. Resertif dalam artian dengan membaca individu dapat memperoleh informasi, ilmu pengetahuan dan pengalaman-pengalaman baru. Semua diperoleh dengan cara membaca yang memungkinkan individu mampu mempertinggi daya pikirannya, berpandangan luas dan juga wawasannya. Oleh karena itu pelajaran membaca merupakan hal 
Novalia Ungzilatun Nikmah, Yuli Darwati, Upaya Peningkatan Kemampuan Membaca Melalui Buku Cerita Bergambar Pada Anak Usia Dini

mendasar dan penting untuk diberikan kepada anak-anak, yang seharusnya ditempa sedari awal agar anak mampu membaca dengan lancar dan memahami maksud bacaan.

Menurut (Yunus 2012) mendefinisikan membaca merupakan seluruh aktivitas yang dilakukan pembaca untuk memperoleh informasi yang terkandung dalam sebuah bacaan. Produk membaca yakni pemahaman atas isi bacaan. Kegiatan membaca bukan hanya sekedar aktivitas pasif saja melainkan pembaca secara aktif berpikir mencari makna dari teks, memahami bahasa itu sendiri dan selembar teks tanpa pemahaman makna yang baik tidak akan berarti apa-apa. ${ }^{1}$

Banyak faktor yang mempengaruhi terhadap kemampuan membaca. Pada umumnya kemampuan membaca ditujukan oleh pemahaman seseorang pada bacaan yang dibacanya dan tingkat kecepatan yang dimiliki. Faktor lain adalah kemampuan intelegensi, kemampuan berbahasa, sikap dan minat, keadaan bacaan, kebiasaan, pengetahuan tentang membaca, latar belakang sosial, ekonomi dan budaya serta emosi. Namun faktor khusus untuk saat ini adalah kondisi pandemi covid-19.

Melihat kondisi pandemi di masa sekarang ini yang tidak memungkinkan guru untuk bertemu secara langsung atau lembaga mengadakan pembelajaran di sekolah seperti pada umumnya. Sehingga pembelajaran dilakukan secara daring atau melalui media online. Guru memiliki banyak hal yang bisa diberikan kepada para muridnya salah satunya dengan pembelajaran media buku cerita. Kecerdasan bahasa atau linguistik merupakan hal penting dan mendasar yang harus dimiliki setiap anak. Namun pada kenyataannya banyak sekali permasalahan yang muncul mengenai perkembangan bahasa ini (Tarigan 1985). ${ }^{2}$

\footnotetext{
1 Yunus Abidin. Pembelajaran Membaca Berbasis Pendidikan Karakter. Jurnal Pendidikan Karakter, 2012, 148.

2 Tarigan. Pengajaran Gaya Bahasa. Bandung: Angkasa. 1985
} 
Permasalahan yang sering didapati oleh peneliti saat di lapangan seperti anak belum mampu mengungkapkan dan mengekspresikan perasaan dan gagasan melalui kemampuan berbahasa, ada yang masih malu berbicara, ada yang kesulitan berbicara dan ada juga yang belum mampu menyimak aktif, kurang memahami perintah yang diberikan guru, tidak berani tampil di depan umum sehingga hal ini mengganggu perkembangan anak dan mengakibatkan anak belum mampu membaca dengan benar dan tepat.

Anak yang belum mampu membaca akan kesulitan meresapi dan memahami maksud dari bacaan. Maka diperlukan adanya pembelajaran membaca lebih ekstra. Pembelajaran atau usaha yang dapat diberikan kepada anak usia dini adalah dengan membaca buku cerita bergambar. Kehadiran buku cerita bergambar menjadi sesuatu yang umum dan sangat disukai oleh anak-anak. Dipakai juga sebagai salah satu sumber pembelajaran yang menarik karena cerita dapat divisualisasikan dengan gambar dan warna-warna yang menarik sesuai dengan alur dan latar cerita.

Kegiatan observasi dilakukan di Taman Baca Pelangi yang merupakan bimbingan belajar untuk anak TK-SD/MI. Meskipun bernama Taman Baca namun berfokus pada kemampuan kognitif, seperti menghitung, mengerjakan soal-soal yang diberikan guru disekolahnya dan kebanyakan anak belum mampu membaca dengan baik. Bukan hanya anak TK saja yang belum mampu membaca bahkan banyak anak kelas 13 SD/MI belum mampu membaca sama sekali. Untuk itulah penelitian ini sangat penting dilakukan. Dari latar belakang yang telah diuraikan diatas maka rumusan masalah dalam penelitian ini adalah 1) Apakah penggunaan buku cerita bergambar dapat meningkatkan kemampuan baca anak? 2) Bagaimana langkah atau metode yang akan digunakan untuk meningkatkan kemampuan baca anak melalui buku cerita bergambar. 
Novalia Ungzilatun Nikmah, Yuli Darwati, Upaya Peningkatan Kemampuan Membaca Melalui Buku Cerita Bergambar Pada Anak Usia Dini

\section{METODE PENELITIAN}

Penelitian ini menggunakan metode PAR (Parcipatory Action Research). Metode penelitian ini merupakan pendekatan yang prosesnya bertujuan untuk pembelajaran dalam mengatasi masalah meningkatkan belajar serta pembelajaran di masyarakat. Metode PAR sendiri merupakan salah satu model pendekatan atau paradigma pembangunan yang menempatkan penelitian menjadi bagian integral dalam pembangunan. Pendekatan ini dipandang sebagai paradigma pembangunan baru menggantikan pembangunan yang to-down (proyek yang ditentukan dari atas) menjadi paradigma pembangunan yang buttom-up (proyek ditentukan oleh masyarakat).

Penelitian ini dilakukan untuk meningkatkan kemampuan baca anak melalui buku cerita bergambar. Penelitian ini dilakukan di salah satu bimbingan belajar Taman Baca Pelangi yang diadakan untuk anak tingkat TK sampai SD/MI di salah satu rumah warga di desa Kalirong Kecamatan Tarokan Kabupaten Kediri. Sampel dari penelitian ini adalah anak TK sampai SD/Ml yang belum mampu membaca.

Langkah yang kami lakukan pertama adalah observasi langsung ke Desa Kalirong dan melakukan wawancara kepada pemilik salah satu bimbingan belajar serta beberapa wali murid atau orang tua anak. Kemudian setelah mendapat berbagai permasalahan dari hasil wawancara kami mensosialisasikan program membaca yang efektif di salah satu bimbingan belajar setempat melalui media buku cerita bergambar untuk peningkatan membaca anak. Langkah ini kami ambil karena buku cerita yang mudah didapat dan dapat digunakan untuk berlatih secara berulang.

Langkah berikutnya adalah perancangan program yang telah disepakati bersama anggota KKN dan pemilik bimbingan belajar serta orang tua anak. Program yang kami lakukan adalah memberikan contoh cara membaca yang benar melalui buku cerita. Kami membacakan terlebih 
dahulu dimulai dari mengeja hingga membaca dalam kalimat utuh. Kemudian dibaca secara individu oleh anak, tidak hanya satu kali baca namun beberapa kali pertemuan kami melakukan treatment yang sama. Dari beberapa program yang telah dibuat dan disepakati diharapkan dapat terjadi peningkatan dalam pemahaman membaca anak.

Setalah diberikan perlakuan yang sama, ternyata masih terdapat beberapa anak yang sedikit lambat menerima perlakuan. Akhirnya kami membuat program reward berupa stiker keberhasilan bagi mereka yang mampu membaca dengan tepat dan benar. Mengingat semangat anak yang luar biasa kami beserta masyarakat sekitar berinisiatif membuat program tambahan berupa lomba membaca dengan hadiah yang menarik agar anak lebih terpacu mengikutinya dan meningkatkan kemampuan baca.

\section{KERANGKA TEORI}

Penggunaan buku cerita bergambar merupakan pilihan yang tepat bagi anak. (Scull J. 2013). Di mana melalui membaca buku cerita bergambar dapat menstimulus anak untuk mengembangkan kemampuan bahasa atau kecerdasan linguistiknya. Kegiatan membaca buku cerita bergambar ini dapat memberikan pengalaman yang unik dan menarik untuk anak. Terlebih jika anak menguasai cerita maka anak dapat menyerap pesan yang terkandung di dalamnya termasuk mengungkapkan emosi yang ada pada buku cerita tersebut. ${ }^{3}$

Anak usia dini adalah anak yang berada pada rentang usia 0-5 tahun. Pada masa ini disebut dengan Golden Age atau masa keemasan. Pada masa keemasan, anak mulai peka atau sensitive terhadap berbagai rangsangan dan sangat menyukai buku cerita dengan gambar-gambar yang menarik. Usia dini juga dikenal sebagai masa awal mengalami

${ }^{3}$ Scull, et al. Young Learners: Teachers' Questions and Prompt as Oppurtunities for Childern's laguange development. University of Mealbourne, Deakin University, and University of Mealbourne. Research in Early Childhood. Vol. 8 No.7, 2013, 71 
Novalia Ungzilatun Nikmah, Yuli Darwati, Upaya Peningkatan Kemampuan Membaca Melalui Buku Cerita Bergambar Pada Anak Usia Dini

pertumbuhan dan perkembangan yang pesat dalam bidang fisik motorik, sosio emosional, koginitif, bahasa, agama dan moral. Menurut (Berk 2012) bahwa anak usia dini dalam rentang usia 4-5 tahun berada pada tahap pra operasional konkret. ${ }^{4}$

Perkembangan kognitif anak dimulai dari yang konkrit menuju abstrak. Hal ini berarti cara berpikir anak masih dibantu oleh benda-benda atau objek yang nyata serta melalui peristiwa yang dialami dan dilihatnya. Buku cerita bergambar dimanfaatkan sebagai sarana pembelajaran bagi anak untuk bisa berpikir dari yang konkrit ke abstrak. Buku cerita bergambar juga lebih mudah untuk pengenalan kosa kata baru yang dibantu dengan ilustrasi menarik pada gambar. Dengan demikian anak akan lebih cepat dan mudah mengenal kata dan gambar secara jelas. Mereka akan mampu mengingat secara abstrak ke dalam pikiran mereka apabila cerita diulang kembali. ${ }^{5}$

Anak-anak sangat menyukai cerita bergambar menurut Hurlock dalam Faizah karena beberapa alasan diantaranya, yaitu: 1) lewat cerita anak mendapat kesempatan untuk mengenal masalah pribadi dan sosialnya. 2) cerita bergambar menuntun imajinasi dan menarik rasa ingin tahu anak. 3) mudah dibaca dan dipahami anak. 4) buku cerita bergambar sudah umum dan tidak sulit ditemukan. 5) buku cerita distimulus oleh gambar agar anak tertarik membaca. 6) cerita dibuat berbentuk serial, sehingga mendorong rasa penasaran anak. 7) tokoh dalam cerita sering menunjukkan perilaku yang membuat anak berpikir langkah berikutnya dari cerita. 8) karakter tokoh yang kuat, berani, tampan dan cantik sehingga dapat dijadikan tokoh andalan anak. 9) gambar yang disajikan penuh warna dan sederhana. ${ }^{6}$

4 Sofia Hartati. Perkembangan Belajar pada Anak, Jakarta: Depdiknas, 2005, 11

${ }^{5}$ Berk, Laura E. Development Trough the Lifespan. Yogyakarta: Pustaka Pelajar. 2012

6 Umi Faizah. "Keefektifan Cerita Bergambar untuk Pendidikan Nilai dan Keterampilan Berbahasa dalam Pembelajaran Bahasa Indonesia". Jurnal Cakrawala Pendidikan, Th XXVIII, No. 3. (Online), 2009, 245. 


\section{TEMUAN DAN PEMBAHASAN}

Dalam hal ini akan dijelaskan tentang kegiatan yang dilakukan peneliti untuk menjawab permasalahan yang telah disebutkan diaatas. Penelitian ini melengkapi peneltian-penelitian terdahulu yang dilakukan oleh Mutia Afrida, Fakriah dan Dewi Fitiani di sebuah TK A di Banda Aceh menunjukkan adanya hasil atau perubahan yang signifikan terhadap minat baca anak. Guru memanfaatkan penggunaan buku cerita bergambar dalam pengembangan bahasa anak. Begitu pula dengan penelitian yang dilakukan oleh Lina Marita Zona di TK Pertiwi 1 Tirtobangun Kabupaten Nganjuk bahwa hasil penelitian dengan penggunaan buku cerita bergambar dapat meningkatkan kemampuan membaca anak kelompok TK B. ${ }^{7}$ Berdasarkan penelitian terdahulu dengan melihat adanya hasil yang signifikan maka penelitian ini dilaksanakan dengan menggunakan metode tindakan langsung yang terdiri dari beberapa tahapan yaitu:

1. Perencanaan, yang meliputi wawancara kepada pemilik bimbingan belajar setempat dan orang tua, menyiapkan lembar observasi, menetapkan program membaca buku cerita, menyusun beberapa tugas untuk anak, menyiapkan beberapa reward, membuat hasi evaluasi.

2. Pelaksanaan tindakan, meliputi menerapkan secara langsung program yang telah disusun, pembelajaran awal yang telah disusun menggunakan media gambar dilaksanakan setiap hari senin sampai jumat, uji coba dilakukan minggu pertama dan kedua. Pembelajaran berikutnya kami memberikan reward bagi peserta atau anak yang memiliki kemampuan baca yang unggul berupa stiker keberhasilan, Kemudian pada tahap terakhir selain pemberian reward kami melaksanakan beberapa lomba demi mengasah dan mempertajam kemampuan baca anak.

7 Mutia Afnida dan Dewi Fitriani. Penggunaan Buku Cerita Bergambar dalam Pengembangan Bahasa Anak pada TK A di Banda Aceh. Jurnal IImiah Mahasiswa Pendidikan Anak Usia Dini. Vol. 1 No. 3. 2016 
Novalia Ungzilatun Nikmah, Yuli Darwati, Upaya Peningkatan Kemampuan Membaca Melalui Buku Cerita Bergambar Pada Anak Usia Dini

3. Hasil observasi aktivitas baca anak, selama pelaksanaan penelitian kami melakukan pencatatan dengan menggunakan daftar observasi (check list)

Tabel 1 Analisis hasil evaluasi kemampuan baca anak sebelum tindakan

\begin{tabular}{|c|c|c|c|c|c|c|}
\hline \multirow[t]{2}{*}{ No. } & \multirow[t]{2}{*}{ Nama Anak } & \multicolumn{3}{|c|}{ Aspek yang dinilai } & \multirow[t]{2}{*}{ Skor } & \multirow[t]{2}{*}{ Nilai } \\
\hline & & Kelancaran & Intonasi & Artikulasi & & \\
\hline 1. & Afrizal & 6 & 6 & 5 & 17 & 72 \\
\hline 2. & Affan & 7 & 5 & 7 & 19 & 75 \\
\hline 3. & Ahmad & 7 & 6 & 6 & 19 & 75 \\
\hline 4. & Alinka & 8 & 6 & 8 & 22 & 83 \\
\hline 5. & Ardi & 5 & 6 & 5 & 16 & 70 \\
\hline 6. & Aufa & 6 & 5 & 6 & 17 & 72 \\
\hline 7. & Auliya & 7 & 7 & 7 & 21 & 82 \\
\hline 8. & Azril & 6 & 6 & 6 & 18 & 74 \\
\hline 9. & Bafadhol & 7 & 6 & 7 & 20 & 80 \\
\hline 10. & Fajar & 6 & 5 & 7 & 18 & 74 \\
\hline 11. & Habib Wahyu & 6 & 6 & 7 & 19 & 75 \\
\hline 12. & Habibi & 7 & 7 & 7 & 21 & 82 \\
\hline 13. & Hanif & 7 & 6 & 6 & 19 & 75 \\
\hline 14. & Ichsan & 6 & 5 & 6 & 17 & 72 \\
\hline 15. & Iftina & 7 & 7 & 6 & 20 & 80 \\
\hline 16. & Nabila & 6 & 6 & 7 & 19 & 75 \\
\hline 17. & Rofik & 5 & 5 & 4 & 14 & 65 \\
\hline 18. & Ufi & 7 & 8 & 8 & 23 & 84 \\
\hline 19. & Zhean & 6 & 5 & 6 & 17 & 72 \\
\hline 20. & Zidan & 6 & 6 & 5 & 17 & 72 \\
\hline
\end{tabular}

Berdasarkan hasil treatment awal banyak terdapat anak yang kurang dalam kemampuan baca. Penerapan membaca awal ini bertujuan menciptakan anak lebih aktif dalam media pembelajaran. Selain kelancaran dan ketepatan baca kami mengharapkan mereka mampu memahami cerita dan meluapkan emosi yang terkandung dalam cerita. Namun pada tahap 1 terlihat belum maksimal maka peneliti melanjutkan program membaca pada tahap berikutnya. 
Tabel 2 Analisis hasil evaluasi kemampuan baca anak setelah tindakan

\begin{tabular}{|c|l|c|c|c|c|c|}
\hline \multirow{2}{*}{ No. } & \multirow{2}{*}{ Nama Anak } & \multicolumn{3}{|c|}{ Aspek yang dinilai } & \multirow{2}{*}{ Skor } & Nilai \\
\cline { 3 - 5 } & & Kelancaran & Intonasi & Artikulasi & & \\
\hline 1. & Afrizal & 7 & 6 & 6 & 19 & 75 \\
\hline 2. & Affan & 8 & 6 & 7 & 21 & 82 \\
\hline 3. & Ahmad & 8 & 6 & 8 & 22 & 83 \\
\hline 4. & Alinka & 9 & 9 & 9 & 27 & 89 \\
\hline 5. & Ardi & 7 & 6 & 6 & 19 & 75 \\
\hline 6. & Aufa & 8 & 7 & 6 & 21 & 82 \\
\hline 7. & Auliya & 9 & 8 & 9 & 26 & 88 \\
\hline 8. & Azril & 7 & 6 & 6 & 19 & 75 \\
\hline 9. & Bafadhol & 8 & 7 & 7 & 22 & 83 \\
\hline 10. & Fajar & 7 & 6 & 7 & 20 & 80 \\
\hline 11. & Habib Wahyu & 7 & 7 & 7 & 21 & 82 \\
\hline 12. & Habibi & 9 & 9 & 9 & 27 & 89 \\
\hline 13. & Hanif & 8 & 7 & 7 & 22 & 83 \\
\hline 14. & Ichsan & 7 & 6 & 6 & 19 & 75 \\
\hline 15. & Iftina & 9 & 8 & 8 & 25 & 86 \\
\hline 16. & Nabila & 8 & 8 & 8 & 24 & 85 \\
\hline 17. & Rofik & 6 & 6 & 6 & 18 & 70 \\
\hline 18. & Ufi & 9 & 9 & 9 & 27 & 89 \\
\hline 19. & Zhean & 7 & 7 & 8 & 22 & 83 \\
\hline 20. & Zidan & 7 & 6 & 6 & 19 & 75 \\
\hline
\end{tabular}

Berdasarkan hasil dari tabel 2 terlihat perubahan yang cukup signifikan. Dimana anak mendapat kemajuan dan peningkatan dalam membaca dan memahami buku cerita. Dari hasil observasi yang diperoleh menunjukkan bahwa peneliti telah melakukan pembelajaran dengan baik. Banyak anak lebih termotivasi dengan adanya reward tersebut.

Dari hasil pengolahan dan analisis data baik dari pengamatan tabel 1 dan 2 secara keseluruhan terdapat perubahan yang sangat signifikan. Peningkatan yang cukup signifikan ini dikarenakan kekurangan pada tabel 1 diperbarui dengan strategi baru yakni menggunakan buku cerita bergambar dan reward. 
Novalia Ungzilatun Nikmah, Yuli Darwati, Upaya Peningkatan Kemampuan Membaca Melalui Buku Cerita Bergambar Pada Anak Usia Dini

\section{KESIMPULAN}

Berdasarkan hasil penelitian diatas dapat disimpulkan bahwa:

1. Adanya peningkatan kemampuan membaca melalui media gambar dalam proses pembelajaran.

2. Metode pemberian reward kepada anak dapat menambah semangat dalam membaca

Peneliti memberikan saran kepada para guru hendaknya diberikan pembinaan khusus tentang membaca dan diperlukannya peran orang tua untuk memantau perkembangan anak.

\section{DAFTAR PUSTAKA}

Abdurrahman, Mulyono. 2003. Pendidikan Bagi Anak Berkesulitan Belajar. Jakarta: Rineka Cipta.

Berk, Laura. 2012. Development Trough the Lifespan. Yogyakarta: Pustaka Pelajar.

Elizabeth, A. Hurlock. 1997. Perkembangan Anak Jilid 1. Jakarta: Erlangga.

Faizah, Umi. 2009. "Keefektifan Cerita Bergambar untuk Pendidikan Nilai dan Keterampilan Berbahasa dalam Pembelajaran Bahasa Indonesia." Jurnal Cakrawala Pendidikan Th XXVIII No. 3.

Gibbons. 1993. Learning to Learn in a School Language. Australia: Heinemann Porthmourth $\mathrm{NH}$.

Hartati. 2005. Perkembangan Belajar pada Anak. Jakarta: Depdiknas.

Istiyani. 2013. "Model Pembelajaran Membaca Menulis Berhitung (CALISTUNG)." Jurnal Penelitian Vol. 10 No. 1.

Laura E, Berk. 2012. Development Trough the Lifespan. Yogyakarta: Pustaka Pelajar.

Mei Ratnasari Eka, Enny Zubaidah. 2019. "Pengaruh Penggunaan Buku Cerita Bergambar Terhadap Kemampuan Berbicara Anak." Jurnal Pendidikan dan Kebudayaan Volume. 9 No. 3.

Mulyasa, H. E. 2009. Praktik Penelitian Tindakan Kelas. Bandung: Remaja Rosdakarya. 
Mutia Afnida, Dewi Fitriani. 2016. "Penggunaan Buku Cerita Bergambar dalam Pengembangan Bahasa Anak pada TK A di Banda Aceh." Jurnal IImiah Mahasiswa Pendidikan Anak Usia Dini Volume. 1 No. 3.

Scull J., Louise, P., \& Raban, B. 2013. "Young Learners: Teacher's Question and Prompt as Opportunities for Children's Launguage Development." University of Melbourne, Deakin University Research in Early Childhood 69-91.

Tarigan. 1985. Pengajaran Gaya Bahasa. Bandung: Angkasa.

Yunus, Abidin. 2012. "Pembelajaran Membaca Berbasis Pendidikan Karakter." Jurnal Pendidikan Karakter 148.

Yusuf, Abidin. 2012. "Pembelajaran Membaca Berbasis Pendidikan Karakter." Jurnal Pendidikan Karakter 148.

Yusuf, Syamsu. 2009. Psikologi Perkembangan Anak dan Remaja. Bandung: Remaja Rosdakarya. 